\title{
HEARTS AND MINDS CANNOT BE BOUGHT: INEFFECTIVE RECONSTRUCTION IN
}

\section{AFGHanistan}

\section{Travers B. Child}

Travers Barclay Child is affiliated with the Department of Development Economics, VU University and the Tinbergen Institute in The Netherlands. He may be reached at t.b.child@vu.nl.

\section{Abstract}

Recent work has suggested the foreign-led reconstruction effort carried out in Afghanistan and Iraq can mitigate violence because it helps win the "hearts and minds" of local people. For the case of Afghanistan, we show there is no evidence behind such an assertion. Analyzing unique data on Commander's Emergency Response Program (CERP) spending across the country from 2005 to 2009, we find no discernible effect of the reconstruction effort on violence. In light of the absence of empirical evidence for the success of the CERP, we suggest the hearts and minds credo currently guiding U.S. policy be reconsidered.

$\mathrm{I}$ n the wake of the April 2014 Afghan presidential election, it was unclear whether the highly anticipated U.S.-Afghanistan Bilateral Security Agreement (BSA) would be signed by the incoming Afghan president and, if so, what form it would take. ${ }^{1}$ In the absence of such an agreement, NATO combat troops continue their complete withdrawal scheduled by the end of 2014. As international security forces draw down, reconstruction and aid programs follow suit. Internationally funded development projects have constituted a considerable share of total Afghan economic activity in recent years, so many people fear their recession will have unwanted security ramifications. Importantly, though, it is debatable whether reconstruction work was ever helpful to stability in the first place.

At face value, attacks on coalition forces have risen along with the volume of reconstruction work carried out in Afghanistan and Iraq, and yet foreign-led reconstruction programming has proceeded steadfast. Since the beginning of the invasions, the U.S. government alone has spent over USD100 billion and over USD80 billion, respectively, in Afghanistan and Iraq. Reconstruction funds have been doled out under the hearts and minds credo, which maintains that economic development improves community cooperation in the fight against rebels and provides alternative economic opportunities for would-be insurgents. In fact, the U.S. Army Marine Corps Counterinsurgency Field Manual explicitly incorporates reconstruction work as a mainstay of counterinsurgency (COIN) strategy. But empirical evidence for the effectiveness of reconstruction spending in reducing violence is extremely limited. ${ }^{2}$

This article puts the hearts and minds perspective of counterinsurgency to the test by measuring the impact of U.S. military-administered reconstruction spending on violence in Afghanistan. In light of improved access to Commander's Emergency Response Program (CERP) data, the article revisits previous work in this journal (Chou, 2012) by using a much longer time frame of study (57 months instead of 4) and broader geographical coverage (227 districts as opposed to 202). We study whether the estimates previously obtained are imprecise due to sample size limits, or because CERP truly has failed to generate stability in Afghanistan. We show the effect of CERP spending on violence in Afghanistan is statistically indistinguishable from zero. In fact, the spending coefficient is actually positive, casting further doubt on the effectiveness of CERP. Distinguishing between small and large projects still does not yield statistically precise estimates, but the coefficient values do suggest large projects may be responsible for any potential adverse effects of CERP programming.

The following section elaborates the empirical challenges faced by the hearts and minds perspective. Our data on reconstruction and violence across Afghanistan is then detailed. Thereafter, the hearts and minds theory is put to test by measuring the impact of CERP spending on violence in Afghanistan. We conclude with a discussion of the results and their implications.

Tribulations of "hearts and minds" research

The hearts and minds perspective guiding U.S. counterinsurgency efforts maintains that reconstruction and development work is pacifying. Broadly, the channels are twofold: (1) the hearts of the people are won through the provision of public goods and (2) their minds are conquered with economic opportunity. This latter premise forms the basis of opportunity cost models of conflict. That theoretical camp 
portrays conflict as an economic activity with opportunity cost. The more attractive are employment options in the licit sector, the more likely are the insurgents to defect from paid rebellion. Reconstruction and development projects increase the payoff and prevalence of formal sector work and thus are expected to increase stability. While this theoretical characterization of violent political resistance is readily embraced by economists, the empirical evidence for economic drivers of conflict is highly contested. One early landmark paper presented cross-sectional country level evidence that violent conflict correlates with economic aggregates. This result was overturned by later work, however, introducing country fixed effects, thereby accounting for the possibility that both economic growth and conflict are determined by underlying political and institutional factors. Some micro-level evidence has supported opportunity cost models of rebellion, but other work has cast doubt on their validity. Taken together, there is scant evidence for conquering minds with economic growth in conflict areas. ${ }^{3}$

Another prong of the hearts and minds theory (enumerated above) was recently formalized with a theoretical innovation by Berman, Shapiro, and Felter (BSF, 2011). In appreciation of public goods brought through development, the population shares information with the (acting) government in the fight against insurgents. In this framework, "aid conditionality is an essential ... prerequisite for stability-enhancing development." Public goods are provided conditional on community support (i.e., information about insurgents). If the benefits derived from reconstruction spending sufficiently offset the negative repercussions of opposing rebel forces, then the community cooperates with the government, thereby enabling it to more effectively quell insurgency. Empirical tests of the information-sharing theory above have focused on projects in the Commander's Emergency Response Program (CERP). Funding under this program is doled out by U.S. commanders on the ground and is therefore thought to fulfill the conditionality requirement critical to this theory. Small projects are expected to be most effective at leveraging community support because their financing is less constrained by bureaucratic oversight. BSF (2011) provide evidence that CERP spending does mitigate violence in Iraq, but only during a period of increased troop strength (while spending is ineffective in the remaining majority of sample years). However, the authors do not test whether community-provided information is more forthcoming in the face of increased reconstruction spending, or whether information tempers the effectiveness of counterinsurgency. ${ }^{4}$

In a previous issue of this journal, Chou (2012) replicates the BSF (2011) analysis for the case of Afghanistan, arguing in
Using Commander's Emergency Response Program (CERP) data covering 57 months and 227 geographic districts, the article shows that the effect of CERP spending on violence in Afghanistan is statistically indistinguishable from zero. Distinguishing between small and large projects still does not yield statistically precise estimates.

support of the information-sharing theory. Although no statistically significant violence-reducing effects of CERP are revealed, the relevant coefficient is negative in sign, which is used to suggest CERP projects may reduce violence. The issue of statistical insignificance is put down to the relatively short sample period (4 months in 2009-2010), which can inflate standard errors.

According to the information-sharing theory, the channel through which reconstruction is expected to translate into stability is community support. It has been shown, however, that development projects have (if anything) a negative effect on Afghan attitudes toward foreigners. Although projects increase perceptions of state capacity, they also increase perceived violence. Interestingly, other evidence suggests that National Solidarity Program (NSP) spending improves community perceptions of government in Afghanistan and may translate into reduced violence. Importantly, NSP is of an altogether different nature than CERP. Since NSP projects are selected by locally elected community development councils, with funding commitments predetermined, making projects unconditional, NSP constitutes exactly the type of programming that should have no effect on violence according to the information-sharing theory. These findings cast doubt on the causal mechanism linking reconstruction to stability from the hearts and minds perspective. Our own findings exacerbate this doubt since even the reduced form relationship between reconstruction spending and violence breaks down when using our expanded data on CERP spending in Afghanistan. ${ }^{5}$

\section{Data on violence and reconstruction spending}

Throughout the analysis our dependent variable is violence, which we measure using the Worldwide Incidents Tracking System (WITS). This is a U.S. government database assembled by National Counterterrorism Center analysts. Data are gleaned manually from open media sources, including local media where linguistic capabilities permit. WITS catalogues all publicly known, premeditated, politically motivated violence directed at police, military, government, and civilians "outside of war-like settings," but includes ambushes, suicide attacks, and use of improvised explosive devices (IEDs). The data cover incidents in Afghanistan from 2005 until August 2009 and has been geocoded by the Empirical Studies of Conflict 
Project at Princeton University. Using the ESRI World Gazetteer and digital mapping software, we are able to district-locate 3,599 incidents included in WITS. ${ }^{6}$

In line with related research, our measure of violence does not capture actions initiated by the state such as police raids or counterinsurgency operations. Moreover, in keeping with the previous focus on government-targeted attacks, the vast majority of incidents in WITS involve noncivilian casualties (often exclusively). Because the U.S. military's Combined Information Data Network Exchange (CIDNE) database used by Chou (2012) is not publicly available, and because our sample period merely borders but does not overlap with that of Chou (2012), replication of previous work is not possible. It is worth noting that WITS holds much fewer incidents than does CIDNE. The latter includes all incidents in which government or foreign troops are targeted by enemy combatants; the former includes only those cases which occur "outside of war-like settings." Thus, WITS should comprise a subset of CIDNE events, supplemented with attacks on softer targets such as politicians, contractors, and security guards. The practical implication of this distinction is not immediately clear, but the technical implication is one of classification, leading CIDNE to more comprehensively cover attacks on hard targets.

CERP spending data comes from NATO C3 Agency's Afghanistan Country Stability Picture (ACSP). ACSP is a comprehensive database on reconstruction and development projects across Afghanistan from 2002 to 2009. It was developed for use by NATO, the Government of the Islamic Republic of Afghanistan, and civilian actors. The database contains detailed project information, including cost, timing, and location. While ACSP falls short of providing complete coverage of all reconstruction programs, CERP data is particularly well documented. From 2002 to 2009, ACSP contains data on 8,533 CERP projects worth USD2.2 billion.

Our data coverage is consistent with the USD2.64 billion officially appropriated to CERP between 2004 and 2010. Previous work was based on data covering an alarmingly small subset of true project outlays, at most accounting for USD1.65 million/month in CERP spending. Over the same period, our own data cover projects amounting to USD35.8 million/month, more than a twenty-fold increase in data coverage. On this basis, previous findings suffer from attenuation bias in the best case and ambiguous directional bias in the worst. Our own results are comparatively free of such concerns. ${ }^{7}$

Following Chou (2012), our unit of observation is the district-month. We follow the 2005 Afghan Ministry of the Interior administrative designation of 398 districts spanning 34 provinces. Districts in which CERP was not active during any time of the sample period are omitted from the analysis,
Table 1: Summary statistics

\begin{tabular}{|c|c|c|}
\hline & Obs. & Mean \\
\hline $\begin{array}{l}\text { Violent incidents (per million } \\
\text { inhabitants) }\end{array}$ & 12,939 & 3.24 \\
\hline CERP spending (USD/capita) & 12,939 & 1.61 \\
\hline $\begin{array}{l}\text { Small project spending } \\
\text { (USD/capita) }\end{array}$ & 12,939 & 0.0688 \\
\hline $\begin{array}{l}\text { Large project spending } \\
\text { (USD/capita) }\end{array}$ & 12,939 & 1.54 \\
\hline
\end{tabular}

Notes: Data cover 227 districts over 57 months and are gleaned from the WITS and ACSP databases. Unit of observation is the district-month. Small and large spending categories are subdivisions of total CERP spending. Small projects are less than USD50,000 total cost; large projects exceed that amount. Means are weighted by CSO district population.

leaving 227 districts in a balanced panel of 57 periods. Hence, our sample contains a total of 12,939 observations. Reconstruction spending volumes for a district-month are calculated by summing all daily totals which, in turn, are obtained as the sum of mean daily expenditure over existing projects. Violence levels are obtained by summing all incidents over the respective period. Violence is computed as incidents per 1,000,000 inhabitants. CERP spending is expressed on a per capita basis. District population data is for 2011/12, and is obtained from the Central Statistics Organization (CSO) of the Islamic Republic of Afghanistan. Summary statistics are shown in Table 1.

\section{Ineffectiveness of CERP spending}

In what follows, we carry out a number of econometric tests to measure the effect of CERP reconstruction work on violence. From the hearts and minds perspective, reconstruction spending leads to a decline in violence. According to the information-sharing theory in particular, this causal relationship is strongest when project provision can be made conditional on community cooperation. If the hearts and minds theory has merit in practice, then one should observe a negative coefficient for CERP spending (more spending, less violence). If, instead, there is no connection between reconstruction work and violence, or if the effect of programming on violence is ambiguous, then one should obtain no statistically significant point estimate for CERP spending.

Table 2, Column 1 reports the OLS estimate on the cross-sectional relationship between violence and CERP spending. The coefficient shows a weak, but statistically significant positive relation (more spending, more violence). 
Proponents of the hearts and minds theory suggest the incidence of greater violence in areas heavily concentrated with CERP spending may reflect targeting of reconstruction by the military. Since reconstruction spending is viewed as a tool for peace, projects are naturally set where their benefits are most needed - in volatile regions. To account for this potential endogeneity, Column 2 reports the coefficient using a first-difference approach. This evaluates the within-district change in violence stemming from a within-district change in CERP outlays. For the purpose of comparison with Chou (2012), the estimation allows the time trend to vary by season and by year. Since we use a much longer time frame and broader geographical coverage than Chou (2012), sample size is no longer a statistical concern. The coefficient measuring the impact of CERP spending on violence is not statistically distinguishable from zero. Spending does not appear to affect violence. This finding (or lack thereof) suggests one of two possibilities: (1) the true effect of CERP on violence is nil (the null hypothesis is true), or (2) the true effect of CERP on violence is ambiguous, contingent on factors unaccounted for by the hearts and minds theory and, consequently, the empirical approach adopted here. Since the point estimate on CERP spending is actually positive, further doubt is cast on the program's general effectiveness at reducing violence.

To approach BSF (2011), column 3 allows the time trend of violence to vary by district, and also conditions results on recent instability. The effect of CERP spending on violence appears even more positive than before, and still statistically insignificant. Lastly, to completely align our estimation strategy with the work done on Iraq, data are aggregated up to the half-year level, and seasonal and annual trends are replaced with period-specific trends. ${ }^{8}$ Column 4 allows for slower consolidation of potential effects, yet the results still do not support a violence-reducing role for CERP. At this point, in defense of the information-sharing theory, one might wonder whether CERP outlays are sufficiently conditional on community-provided intelligence such that we can expect to observe peace dividends. To this question we now turn.

Previous research suggests that "small" CERP projects, amounting to less than USD50,000 each, are subject to little bureaucratic oversight and therefore more likely tailored to community needs. Such projects are argued to fulfill the conditionality requirement for reconstruction spending to be violence-reducing under the information-sharing framework. So following previous authors, we decompose CERP spending

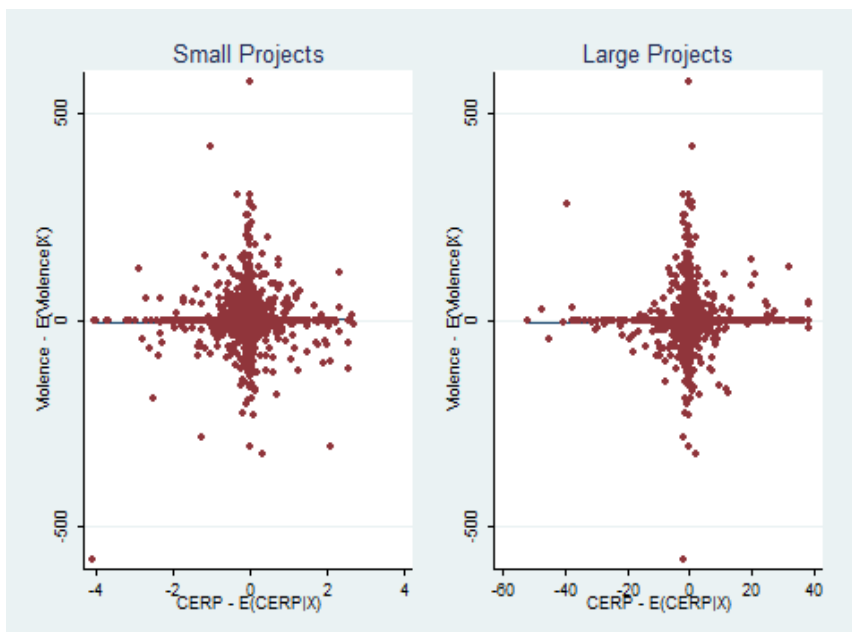

Figure 1: Data cover 227 districts over 57 months and are gleaned from the WITS and ACSP databases. Unit of observation is the district-month. Graphs depict the net relation between violence and CERP spending. Along the $y$-axes is the unexplained change in violent incidents per million inhabitants; along the $x$-axes is the unexplained change in CERP spending per capita. Both variables are expressed as the difference between the observed value and that which is expected, conditional on the full set of remaining covariates. Small and large spending categories are subdivisions of total CERP spending. The left and right added-variable plots are based on regressions reported in columns 1 and 2 of Table 3 , respectively. 
into small and large projects. Figure 1 plots changes in violence against changes in CERP outlays for both types of projects, conditional on all covariates. Spending on small projects does not appear to affect violence differently than spending on large projects (in fact, neither have a discernable effect). Columns 1 and 2 of Table 3 present the numerical analogue to Figure 1, first-difference regression results by project size, allowing for annual, seasonal, and district-specific trends, and controlling for recent instability. The first column reports the coefficient on spending for small projects ( $<$ USD50,000), while the second column tests the impact of large-project spending (>USD50,000). Column 3 includes spending under both size classes simultaneously. Distinguishing between small and large projects in Table 3 does not add explanatory power to the model. The coefficients on all types of spending remain statistically insignificant, again suggesting either validity of the null hypotheses, or ambiguous effects contingent on factors unaccounted for from the hearts and minds perspective. ${ }^{9}$ Due to the divergent coefficient signs across project size classes, it could be that large projects are responsible for any detrimental effect of CERP and that small projects are more likely to be pacifying. However, an F-test does not rule out equality between small and large-project spending coefficients (p-value: 0.39). The estimates in Column 4 again consider aggregation to the six-month interval and do not change the substantive finding.

\section{Conclusion}

Using an econometric method drawn from current literature, this article evaluates the impact of CERP spending on violence across 227 districts in Afghanistan over 57 months from 2005 to 2009. No discernible effect is found. To date there is no empirical evidence that reconstruction spending reduces violence in Afghanistan in accordance with the hearts and minds perspective currently guiding military doctrine, government policy, and public discourse. ${ }^{10}$ Meanwhile, evidence for the effectiveness of CERP in Iraq is tenuous. ${ }^{11}$ Importantly, the literature has so far examined the average effect of CERP, with some distinction made according to project size. Our study suggests either that reconstruction work is unrelated to violence or that programming bears on the insurgency in ways unaccounted for by the hearts and minds perspective, such that an ambiguous average effect masks
Table 3: Violent incidents and CERP spending by project size

$\begin{array}{lcccc}\begin{array}{l}\text { y=incidents per } \\ \text { million population }\end{array} & (1) & (2) & (3) & (4) \\ & & & & \\ \text { CERP (small) } & -0.431 & & -0.458 & -1.108 \\ & (-0.765) & & (-0.817) & (-1.399) \\ \text { CEPR (large) } & & 0.0224 & 0.0242 & 0.000666 \\ & & (1.313) & (1.339) & (0.0213) \\ \text { Year FE } & \mathrm{X} & \mathrm{X} & \mathrm{X} & \\ \text { Quarter FE } & \mathrm{X} & \mathrm{X} & \mathrm{X} & \\ \text { Period FE } & & & & \mathrm{X} \\ \begin{array}{l}\text { District-specific } \\ \text { trend }\end{array} & \mathrm{X} & \mathrm{X} & \mathrm{X} & \mathrm{X} \\ \text { Preexisting trend } & \mathrm{X} & \mathrm{X} & \mathrm{X} & \mathrm{X} \\ \text { Constant } & -0.0812 & -0.0838 & -0.0808 & 8.163 * * * \\ & (-0.474) & (-0.487) & (-0.472) & (3.834) \\ \text { R-squared } & 0.270 & 0.270 & 0.271 & 0.295 \\ \text { p-value for } & - & - & 0.3908 & 0.1635 \\ \beta \text { (small)= } \beta \text { (large) } & & & & \\ \text { Observations } & 12,485 & 12,485 & 12,485 & 1,582 \\ \text { Districts } & 227 & 227 & 227 & 226\end{array}$

Notes: $* * * \mathrm{p}<0.01, * * \mathrm{p}<0.05, * \mathrm{p}<0.1$. Data are gleaned from the WITS and ACSP databases. Unit of observation is the district-month for columns 1-3, and district-half year for column 4. All specifications are first-differenced. Dependent variable is violent incidents per million inhabitants. Small and large spending categories are subdivisions of total CERP spending. Standard errors are clustered by district, and robust t-statistics are in parentheses. All regressions are weighted by CSO district population.

underlying opposing causal forces. In either case, there is scant empirical support for the information-sharing theory which espouses aid conditionality as a guiding principle for recent counterinsurgency efforts.

Given that the United States government has spent over USD180 billion in Afghanistan and Iraq under the hearts and minds credo, we suggest this perspective be reconsidered. New theory is required to identify additional channels through which reconstruction and development work may affect insurgency, in either direction. Only then can we begin to understand which programming characteristics are most likely to generate stability, aside from conditionality which so far seems mostly ineffectual. We push this research agenda with the ultimate aim of keeping military officials and policymakers abreast of empirical knowledge when making important decisions regarding the strategic allocation of reconstruction funds. The benefit of concrete knowledge in this area could be measured in human lives. 


\section{Notes}

The author would like to extend his appreciation to Remco Oostendorp and Chris Elbers for their frequent conceptual and technical guidance throughout the course of this project.

1. Confusion emanates from when the outgoing president, Hamid Karzai, shocked the country and international community through his surprise refusal to sign the Loya Jirga-sanctioned BSA in November 2013.

2. Funding and attacks have risen: U.S. government outlays for reconstruction projects in both countries were increasing from 2003 to 2007 as evidenced by data obtained from the Federal Procurement Data System in 2007. Similarly, data obtained from NATO C3 Agency's Afghanistan Country Stability Picture indicates a consistent increase in outlays to Afghanistan over the period for which data is available (approximately 2002 to 2009). Data from the Global Terrorism Database (GTD) of the National Consortium for the Study of Terrorism and Responses to Terrorism (START) at the University of Maryland indicate a consistent upward trend in violence from the beginning of each respective operation until 2010 (the final year for which GTD data are available). U.S. government outlay figures: SIGAR (2014); SIGIR (2013). Field manual: Civil Security, Civil Control, Essential Services, Governance, and Economic and Infrastructure Development comprise the Stability pillar of COIN strategy (see Figure 1-1, U.S. Army, emphasis added).

3. Opportunity cost models of conflict: Blattman and Miguel (2010) survey such models. Landmark paper: Collier and Hoeffler (2004). Underlying political and institutional factors: Djankov and Reynal-Querol (2010). Some micro-level evidence: Iyengar, Monten, and Hanson (2011); Dube and Vargas (2013). Doubt about validity: Krueger and Malecková (2003); Berrebi (2007); Berman, Callen, Felter, and Shapiro (2011); Nunn and Qian (forthcoming).

4. Quote: Chou (2012). Empirical evidence for Iraq: Berman, Felter, Shapiro, and Troland (2013) provide evidence for complementarity between military control and service provision in reducing violence. Still, no test of the theoretical mechanism in BSF (2011) is offered as information plays no role in the empirical analysis.

5. Negative attitude: Böhnke and Zürcher (2013). NSP spending and reduced violence: Beath, Christia, and Enikolopov (2011).

6. WITS: See Wigle (2010) for a full introduction of the WITS database. WITS data have previously been used, e.g., by Krueger and Malecková (2009).

7. Officially appropriated: SIGAR (2011). Previous work: The USD1.65 million/month figure is calculated by multiplying Chou's (2012) mean per capita monthly expenditure by the maximum population potentially covered by that sample. The latter is taken as the aggregate population of the largest 202 districts in Afghanistan (the number of districts covered by Chou, 2012), amounting to 20,352,400 inhabitants.
8. By aggregating up to the half-year interval, the first three months of the sample are discarded. As a result, we lose one district in which the CERP was only active during those initial months. Hence, we are left with 226 districts over 9 time periods.

9. If despite the statistical insignificance, one nevertheless accepts the point estimates for each spending category in Table 3 , then an increase of one standard deviation in small project spending would reduce violence by 8 percent on average ( 2 percent of a standard deviation) and a standard deviation increase in large project spending would increase violence by 5 percent on average ( 1 percent of a standard deviation).

10. Nevertheless, it remains possible that CERP produced other benefits for Afghans, such as improved access to health services or to public infrastructure.

11. See BSF (2011).

\section{References}

Beath, A., F. Christia, and R. Enikolopov. 2011. "Winning Hearts and Minds? Evidence From a Field Experiment in Afghanistan." MIT Political Science Department Working Paper No. 2011-14. Available at http://www.humansecurity gateway.com/documents/MIT __WinningHeartsand Minds.pdf

Berman, E., M. Callen, J.H. Felter, and J.N. Shapiro. 2011. "Do Working Men Rebel? Insurgency and Unemployment in Afghanistan, Iraq, and the Philippines." Journal of Conflict Resolution. Vol. 55, pp. 496-528. http://dx.doi.org/10.1177/0022002710393920

Berman, E., J.H. Felter, J.N. Shapiro, and E. Troland. 2013. "Modest, Secure, and Informed: Successful Development in Conflict Zones." American Economic Review: Papers \& Proceedings. Vol. 103, No. 3, pp. 512-517. http://dx.doi.org/10.1257/aer.103.3.512

Berman, E., J.N. Shapiro, and J.H. Felter. 2011. "Can Hearts and Minds be Bought? The Economics of Counterinsurgency in Iraq." Journal of Political Economy. Vol. 119, No. 4, pp. 766-819. http://dx.doi.org/10.1086/661983

Berrebi, C. 2007. "Evidence about the Link Between Education, Poverty and Terrorism among Palestinians." Peace Economics, Peace Science and Public Policy. Vol. 13, No. 1. http://dx.doi.org/10.2202/1554-8597.1101

Blattman, C. and E. Miguel. 2010. "Civil War." Journal of Economic Literature. Vol. 48, No. 1, pp. 3-57. http://dx.doi.org/10.1257/jel.48.1.3

Böhnke, J.R. and C. Zürcher. 2013. "Aid, Minds and Hearts: The Impact of Aid in Conflict Zones." Conflict Management and Peace Science. Vol. 30, No. 5, pp. 411-432. http://dx.doi.org/10.1177/0738894213499486

Chou, T. 2012. "Does Development Assistance Reduce Violence? Evidence from Afghanistan." The Economics of Peace and Security Journal. Vol. 7, No. 2, pp. 5-13. 
http://dx.doi.org/10.15355/epsj.7.2.5

Collier, P. and A. Hoeffler. 2004. "Greed and Grievance in Civil War." Oxford Economic Papers. Vol. 56, pp. 563-595.

http://dx.doi.org/10.1093/oep/gpf064

Djankov, S. and M. Reynal-Querol. 2010. "Poverty and Civil War: Revisiting the Evidence." The Review of Economics and Statistics. Vol. 92, No. 4, pp. 1035-1041. http://dx.doi.org/10.1162/REST_a_00046

Dube, O. and J.F. Vargas. 2013. "Commodity Price Shocks and Civil Conflict: Evidence from Colombia." Review of Economic Studies. Vol. 80, No. 4, pp. 1384-1421. http://dx.doi.org/10.1093/restud/rdt009

Iyengar, R., J. Monten, and M. Hanson. 2011. "Building Peace: The Impact of Aid on the Labour Market for Insurgents." NBER Working Paper No. 17297.

Krueger, A.B. and J. Malecková. 2003. "Education, Poverty and Terrorism: Is There a Causal Connection?" The Journal of Economic Perspectives. Vol. 17, No. 4, pp. 119-144. http://dx.doi.org/10.1257/089533003772034925

Krueger, A.B. and J. Malecková. 2009. "Attitudes and Action: Public Opinion and the Occurrence of International Terrorism." Science. Vol. 325, pp. 1534-1536. http://dx.doi.org/10.1126/science.1170867

Nunn, N. and N. Qian. "U.S. Food Aid and Civil Conflict." American Economic Review. Forthcoming.

[SIGAR] Special Inspector General for Afghanistan Reconstruction. January 27, 2011. “Commander's Emergency Response Program in Laghman Province Provided Some Benefits, but Oversight Weaknesses and Sustainment Concerns Led to Questionable Outcomes and Potential Waste." SIGAR Audit-11-7.

[SIGAR] Special Inspector General for Afghanistan Reconstruction. January 30, 2014. Quarterly Report to the United States Congress. http://www.sigar.mil/pdf/quarterly reports/2014Jan30QR.pdf.

[SIGIR] Special Inspector General for Iraq Reconstruction. September 9, 2013. Final Report to the United States Congress. http://www.sigir.mil.

[U.S. Army] The U.S. Army Marine Corps Counterinsurgency Field Manual. 2006.

Wigle, J. 2010. "Introducing the Worldwide Incidents Tracking System (WITS)." Perspectives on Terrorism. Vol. 4, No. 1, pp. 3-23. 